\title{
El poeta Belano alecciona a los maestros
}

\author{
The Belano Poet Lectures the Masters
}

\author{
Marcelo Báez Meza \\ Escuela Superior Politécnica del Litoral, ESPOL \\ Guayaquil, Ecuador
}

Artículo de investigación

https://doi.org/10.32719/13900102.2021.49.3

Fecha de recepción: 20 de abril de 2020

Fecha de aceptación: 20 de mayo de 2020

Licencia Creative Commons

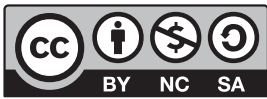




\section{RESUMEN}

Este artículo se concentra en la actitud crítica que Roberto Bolaño tuvo hacia la figura del maestro. Dos personajes destacan en la mira de la ironía bolañesca en la novela Los detectives salvajes: Miguel Donoso Pareja y Octavio Paz. El primero aparece bajo los nombres de Gustavo Pardo y el segundo con su nombre real. Esta actitud iconoclasta se refleja en la subversión como parte de la ética del realismo visceral y recuerda de cierta manera el espíritu de los tzántzicos.

PalABRAS ClAVE: maestro, literatura latinoamericana, Bolaño, Donoso Pareja, novela latinoamericana, real visceralismo.

\section{ABSTRACT}

This article focuses on Roberto Bolaño's critical attitude towards the figure of the master. Two characters stand out in the spotlight of Bolaño's irony in the novel Los detectives salvajes: Miguel Donoso Pareja and Octavio Paz. The former appears under the name of Gustavo Pardo and the latter under his real name. This iconoclastic attitude is reflected in the subversion as part of the ethic of visceral realism and recalls in a certain way the spirit of the Tzántzicos. KEYWORDS: master, latin american literature, Bolaño, Donoso Pareja, latin american novel, visceral realism.

A mediados de la década de 1980 y principios de 1990, hay una proliferación de los talleres literarios en Ecuador. Aparece en la escena cultural ecuatoriana la figura del escritor Miguel Donoso Pareja (19312015), quien retorna de México después de un largo exilio. Asentado en Guayaquil, Donoso Pareja se dedica a replicar los talleres literarios que implementó en México y se convirtió en un referente. Así lo testimonia Juan Villoro, quien fuera su alumno en plena adolescencia:

Un verdadero maestro no solo te brinda conocimientos positivos, sino que te enseña a pensar. En ese sentido, Miguel Donoso no ha dejado de ser mi maestro. Cada texto que he escrito desde los 15 años, edad en la que entré a su taller, han sido una forma de dialogar con él y tener presente su mirada [...]

Su taller fue una escuela de rigor, pero también una búsqueda de la voz propia. Miguel tenía la capacidad de estimular muy diversas virtudes en sus alumnos, dependiendo de las facultades de cada uno. De los 15 a los 19 años me recomendó libros, compartió sus experiencias y me tomó absolutamente en serio, como si yo fuera ya un escritor formado. (Guzmán 2014) 
Como prueba de su afecto al maestro, Villoro asistió en 2014 al lanzamiento en Quito de Cuentos completos de Miguel Donoso Pareja que publicó el Fondo de Cultura Económica. En las entrevistas que el escritor mexicano concedió en Ecuador no cesaron sus palabras de gratitud hacia su mentor que luchaba contra una grave enfermedad los últimos meses de su vida. La declaración que más llama la atención (en la misma entrevista que le hace diario El Comercio de Ecuador) es la que involucra a Roberto Bolaño (1953-2003) y su desinterés en cualquier figura tutelar:

Fui muy amigo de Roberto Bolaño y una de mis pocas diferencias con él era su renuencia a reconocer maestros. Le gustaba verse como alguien que se había formado a sí mismo en soledad, con valentía de pionero. Yo creo que lo mejor de mi vida han sido mis maestros. Donoso Pareja fue el primero de ellos. Me dio la bienvenida a la literatura, a las dificultades que comporta y a los muchos desafíos que deben asumirse en su nombre. (Guzmán 2014)

Estamos ante una definición de maestro que no está distante de aquella que Steiner propone: "El conocimiento es transmisión. En el progreso, en la innovación, por radicales que sean, está presente el pasado. Los Maestros protegen e imponen la memoria" (2011, 27). Las declaraciones de Villoro van en esta línea de proteger la memoria docente y extenderla. Para el mexicano, un maestro enseña a pensar y da la bienvenida a la literatura tratándote como un igual. A todo esto, habría que añadir la categoría de "maestro de lectura", acuñada por el mismo Steiner: "alguien que ha pasado su vida leyendo con los demás” (Jahanbegloo 1994, 85). En este sentido, guiándonos por la primera declaración de Villoro que hemos citado, Donoso Pareja vendría a ser no solo un instructor de un taller literario, también fungió como un orientador de lecturas, entregando a los jóvenes aprendices una brújula bibliográfica.

Pero mientras Villoro es grato con la figura del catedrático, Bolaño es constantemente crítico con la sombra del pedagogo. No tiene estudios formales. Lee por su cuenta, aunque no se considera alguien que se ha enseñado a sí mismo. "Hablar de autodidacta es un error de concepto", declaró en alguna ocasión, “yo leí mucho, hubo autores que me enseñaron lo que sé”. De hecho, se pueden encontrar muchas reseñas periodísticas de 
la "maestría" bolañesca con afirmaciones como "el maestro de la genera-

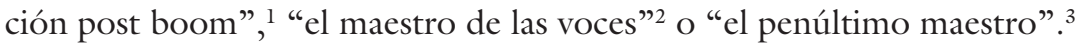

En este punto podría sernos útil la mínima tipología de George Steiner sobre la figura magisterial:

Hay Maestros que han destruido a sus discípulos psicológicamente y, en algunos raros casos, físicamente. Han quebrantado su espíritu, han consumido sus esperanzas, se han aprovechado de su dependencia y de su individualidad. El ámbito del alma tiene sus vampiros. Como contrapunto, ha habido discípulos, pupilos y aprendices que han tergiversado, traicionado y destruido a sus Maestros. $(2011,12)$

Habría que analizar si Bolaño pertenece realmente a esta última categoría, pero cuentos como "Sensini" (homenaje a Antonio di Benedetto), su reivindicación de Nicanor Parra, su deuda con Cervantes saldada en el discurso de aceptación del Rómulo Gallegos, los grandes escritores que aparecen mentados en "Consejos sobre el arte de escribir cuentos", nos impiden verlo como un vampiro tergiversador, traidor y destructor de maestros al que hace referencia Steiner.

El chileno quiere aparecer como un self made man, "con valentía de pionero", según la cita de Villoro, lo cual no está alejado de la verdad. El pionero gusta de explorar territorios desconocidos y alejados. Esta voluntad de indagación (detectivesca al extremo) se atisba en algunas de las obras del chileno como La pista de hielo o Amberes donde la búsqueda es el eje rector, o la persecución a la que los críticos de la primera novela de la saga 2666 someten a Benno von Arcimboldi.

Muchos narradores y poetas egresaron de los talleres literarios en diversos países latinoamericanos, pero a casi nadie se le ocurrió que esa instancia pedagógico-literaria pudiera ser material para ficciones. La premisa de un grupo de aprendices en torno a un maestro ya está en la novela $E l$

1. Obituario de diario El Tiempo de Bogotá al día siguiente de la muerte de Bolaño (16 de julio de 2003). https://www.eltiempo.com/archivo/documento/MAM-968255.

2. "Roberto Bolaño era un maestro de las voces", entrevista a Wilfrido H. Corral (26 de agosto de 2014) en el blog "La perfección ferroviaria". https://laperfeccionferroviaria.wordpress.com/2014/08/26/entrevista-a-wilfrido-corral-rober to-bolano-era-unmaestro-de-las-voces/.

3. "El penúltimo maestro" de Javier Rodríguez Marcos en diario El País del 29 de octubre de 2008. https://elpais.com/diario/2008/10/29/cultura/1225234802_850215. html. 
miedo a los animales (1996) de Enrique Serna y, sobre todo, en Los detectives salvajes (1998), de Roberto Bolaño, que parece contener "los cien talleres [literarios] abiertos como flores en el DF", como dice el personaje Juan García Madero en sus diarios, o disecciona esa "fiebre que nos dio por los talleres", como asevera otro personaje, Jacinto Requena, en uno de los testimonios de esa novela total. La importancia de estos laboratorios literarios es tal que 37 veces se repite la palabra "talleres" a lo largo de sus páginas.

En el cuento "Gómez Palacio" de Putas asesinas (2001), el escritor chileno ya expresa su preocupación por estos espacios de creación y discusión literarias. La voz narrativa en primera persona hace un viaje a la ciudad nombrada en el título, con la finalidad de asumir la posible dirección de unos talleres de escritura. El comienzo rulfiano esconde una historia que luego avanzará con matices irónicos: "Fui a Gómez Palacio en una de las peores épocas de mi vida. Tenía veintitrés años y sabía que mis días en México estaban contados”. Días que luego cifrará en su novela cumbre cuya historia se centrará en el DF con personajes igual de jóvenes y también poetas. Dejemos que sea la voz en primera persona del singular la que permita que nos adentremos en ese mundo polvoriento de "un pueblo perdido del norte de México":

Mi amigo Montero, que trabajaba en Bellas Artes, me consiguió un trabajo en el taller de literatura de Gómez Palacio, una ciudad con un nombre horrible. El empleo acarreaba una gira previa, digamos una forma agradable de entrar en materia, por los talleres que Bellas Artes tenía diseminados en aquella zona. Primero unas vacaciones por el norte, me dijo Montero, luego te vas a trabajar a Gómez Palacio y te olvidas de todo. No sé por qué acepté. Sabía que bajo ninguna circunstancia me iba a quedar a vivir en Gómez Palacio, sabía que no iba a dirigir un taller de literatura en ningún pueblo perdido del norte de México. (Bolaño 2001, 27)

En "Gómez Palacio" también aparece el desierto, esa nada inconmensurable que luego será decisiva en la búsqueda de la legendaria poeta Cesárea Tinajero. El joven veinteañero que protagoniza el cuento divaga: “¿De qué color es el desierto de noche?, me había preguntado días atrás en el motel. Era una pregunta retórica y estúpida en la que cifraba mi futuro, o tal vez no mi futuro sino mi capacidad para aguantar el dolor que sentía”. El desierto se prefigura en esta narración como ese espacio 
de interrogaciones y también de pérdidas que será Sonora en las obras posteriores de Bolaño.

En este mismo cuento aparecen los jóvenes bardos que tanto interesarán al novelista chileno en 2666. Estamos ante uno de los pocos escritores que transpiran poesía y que además exhibe sus vastas lecturas poéticas. No es gratuito que la palabra que más veces se repite en Los detectives salvajes sea "poeta" con 571 menciones.

Una de las más inteligentes lecturas sobre la dimensión poética del escritor chileno es la que ofrece Alejandro Zambra para quien "Los poemas de Bolaño son los poemas que escriben los personajes de Bolaño: el novelista inteligible pone en escena al poeta ininteligible. El narrador hace comprensible al poeta: ligeramente comprensible, apenas comprensible" $(2010,92)$. Curiosa heteronimia la que propone Zambra al señalar que los poemas son extensiones de los personajes y que sin el poeta no existe el narrador y viceversa. Lo uno va ligado a lo otro. Hay cosas que solo se pueden narrar y que no caben en un poema, y al narrar hay cabida para los pincelazos líricos. Lo más importante es que cualquier realidad que esté narrando Bolaño siempre tendrá la lente de la poiesis.

El mejor ejemplo de esta obsesión por la lírica se aprecia en el episodio "Amadeo Salvatierra. Calle República de Venezuela, cerca del Palacio de la Inquisición, México DF, enero de 1976”, en el que se recurre a una larga enumeración de cinco folios de representantes de la vanguardia. Pretextando haber encontrado un directorio de poetas en una revista llamada Actual desfilan nombres ilustres e ilustrados desde Cansinos-Assens y Gómez de la Serna hasta Jean Cocteau y Paul Éluard. Su conocimiento no es simplemente enumerativo por llenar alguna lista o reproducir algún directorio que el autor recabó en alguna hemeroteca. Prueba de su erudición es ver en esa descomunal enumeración el nombre del poeta ecuatoriano Hugo Mayo, incluido por Jorge Luis Borges y Alberto Hidalgo en Índice de la nueva poesía americana (1926).

Los detectives salvajes concentra la voluntad de Bolaño de crear su propio índice de poesía continental. En un polo de ese canon está la figura patriarcal de Octavio Paz y en el otro polo está la matriarca Cesárea Tinajero:

Coincidimos plenamente en que hay que cambiar la poesía mexicana. Nuestra situación (según me pareció entender) es insostenible, entre el 
imperio de Octavio Paz y el imperio de Pablo Neruda. Es decir: entre la espada y la pared. (Bolaño 1998, 30)

Esta anotación de Juan García Madero da cuenta de la situación polarizada que vivió el México literario en los años setenta. Se usa la palabra “imperio" perfectamente acoplado con la idea del César de la poesía. Son dos caudillajes poéticos: el uno es el oficial, el de Cesárea es el alternativo; el primero copa toda la cultura mexicana, la segunda es una poeta de culto sin obra que la respalde, sin poemas que evidencien su estatus de leyenda.

Antes de entrar a analizar esa clara cabeza que fue Paz, regresemos con Donoso Pareja que vendría a ser también una especie de César, al menos en la literatura ecuatoriana por su amplia labor como crítico, editor, narrador y coordinador de talleres literarios. Bolaño y él se conocieron en el DF de los años setenta. El guayaquileño prologó la antología del chileno Muchachos desnudos bajo el arcoiris de fuego: once jóvenes poetas latinoamericanos (1979). En el prefacio se lee la siguiente apreciación sobre la poesía bolañesca:

Bolaño, por su parte, proviene directamente de De Rokha, sobre todo en la grandilocuencia, pero con algunos aditamentos beatniks (no tengo elementos para determinar si a través de Gabriel Carvajal - poeta chileno que escribía baladas como Villon y se identificaba profundamente con Ginsberg - o de su permanencia en México). Como De Rokha, Bolaño tiene una respiración ancha, poderosa.

Fundador con otros poetas - especialmente Mario Santiago- del Infrarrealismo (movimiento sin manifiesto, ${ }^{4}$ como no sería de esperarse en este tipo de actitudes grupales), su poesía se mueve dentro de un "vitalismo" que la mantiene, sin duda, en "proceso". (Donoso Pareja 1979, 32)

Ese principio vitalista, esas actitudes grupales de las que habla Donoso Pareja en la cita podrá admirarse después, en toda su dimensión, en Los detectives salvajes. Se trata de la primera apreciación crítica sobre la poesía del chileno y resulta valiosa porque pone en contexto el quehacer poético de los años setenta. En una veintena de páginas se pasa revista al pensamiento de Saúl Yurkiévich, Fernando Alegría, Aldo Pellegrini y se

4. Donoso Pareja ignora la publicación de Primer manifiesto infrarrealista (1976) en la revista Correspondencia Infra de la cual apareció solamente un número (octubre/ noviembre de 1977) con un tiraje de 5000 ejemplares. 
hace un inventario muy completo de poetas de la segunda mitad del siglo XX. Hay reflexiones sobre la poesía conversacional, la antipoesía, el llamado exteriorismo, la poesía concreta, el nadaísmo, el infrarrealismo (que en la novela de Bolaño aparecerá con el nombre de realismo visceral), y el estridentismo, tendencia a la que pertenece Cesárea Tinajero.

Bolaño ya había publicado sus versos en Pájaro de calor (1976), además de las ediciones de autor de Gorriones cogiendo altura (1975) y Reinventar el amor (1976) pero sin ninguna valoración crítica directa. Lo importante en el prólogo es la perspectiva del guayaquileño sobre las diversas tendencias de la poesía latinoamericana que fueron asimiladas por los “jóvenes desnudos" aludidos en el título de la antología. Algunas de estas reflexiones serán retomadas posteriormente por algunos críticos (como Javier Campos) que se remitirán siempre al prefacio de Muchachos desnudos... a veces sin citarlo directamente.

Donoso Pareja ve con claridad "tres movimientos jóvenes aparecidos en América del Sur [...]. Me refiero a los nadaístas colombianos, a los tzántzicos, del Ecuador, y al Movimiento Hora Zero del Perú” (1979, 21). Esta tríada de tendencias tendrían su clímax en el grupo de los infrarrealistas de México y se verá recreada en la novela "salvaje" de 1998:

Los tres movimientos, entonces, tienen una secuencia que, más o menos oscilatoria, va construyendo una actitud que redefine lo que las vanguardias de la primera guerra habían planteado: libertad de expresión, rechazo de toda retórica, destrucción de lo viejo y construcción de lo nuevo. $(1979,25-6)$

El guayaquileño parece estar hablando no solo del corsi e ricorsi de la historia (los tiempos cíclicos a los cuales se refería Giambattista Vico) sino también a la tradición de la ruptura, esa actitud circular que tan bien analiza Octavio Paz en Los hijos del limo. En tal caso, el infrarrealismo (del cual Donoso Pareja da una explicación etimológica completamente distinta a todas cuanto circulan) es fundamental para la construcción del mito bolañesco:

De acuerdo con la teoría de Bolaño, el infrarrealismo sirvió para alimentar como tema su obra narrativa y mitologizar ese mundo con Los detectives salvajes, que es una respuesta literaria soberbia a este hecho hasta tal punto de conseguir que una época que quizás no fuera tan 
valiosa trascendiera y engrandeciera gracias a este entramado que le confiere el novelista. (Villoro 2013)

De esta manera hay que ver Los detectives salvajes como una novelización no solo de la etapa del chileno en México sino también de una era importante de la poesía latinoamericana. Es una especie de making of de las corrientes poéticas que abundan en la segunda mitad del siglo XX.

De la tríada de tendencias de las que habla Donoso Pareja nos interesa solamente una. Los Tzántzicos (1960-1969) es un nombre tomado de los indígenas amazónicos que reducían las cabezas de sus enemigos. “Así, el tzantzismo fue más una actitud que una poética y su característica el parricidio. Creía en la acción inmediata de la poesía: tal vez por eso no dieron obra que realmente valiera la pena" (Donoso Pareja 1979, 23).

La poesía que caracterizó a este grupo quiteño era combativa y de corte eminentemente social. Uno de sus principales exponentes fue Ulises Estrella. No discutiremos aquí la coincidencia entre este nombre y el de Ulises Lima. Después de todo en los manuscritos del Archivo Bolaño aparece el nombre de Odiseo Kitu como el concebido originalmente para ese personaje, como una forma de enfatizar su nomadismo y su condición ecuatorial. La vinculación con el movimiento tzántzico ya ha sido examinada después del estudio introductorio de Donoso Pareja, enfatizando la irreverencia de los jóvenes poetas que aparecen en Los detectives salvajes:

De allí que Ulises Lima venga a ser claramente en la novela un poeta cien por cien "tzántzico". En otras palabras, el poeta infrarrealista debía subvertir lo cotidiano a través de una imaginación igualmente subversiva para descubrir mundos nuevos. El poeta debía ser un francotirador, un aventurero. Debía tener otra manera de mirar, opuesta a la mirada complaciente del arte burgués. El poeta debía fijarse en lo diverso del mundo, especialmente en la diversidad de la urbe y asimilarla en su poesía. (Campos 2011)

Este carácter subversivo o tzántzico en la obra bolañesca, insistimos, fue notado y anotado por Donoso Pareja por primera vez en 1979. Hacemos esta referencia porque el guayaquileño aparece en Los detectives salvajes como personaje.

En un artículo titulado "Writing from Neverland", publicado en la revista ecuatoriana El Búho, Leonardo Valencia revela que la novela de Bolaño 
pinta de cuerpo entero a una tropa de poetas mediocres, a la sombra del boom y de los verdaderos poetas, que quisieron hacer de la literatura un terreno de poder. Vean, por ejemplo, el retrato despiadado (páginas 205 y siguientes) que hace de un novelista ecuatoriano radicado en México al que llama Gustavo Vargas Pardo y que, por supuesto, no está basado en Demetrio Aguilera Malta ni Vladimiro Rivas como me aclaró el mismo Bolaño cuando le pregunté por ese personaje. (Valencia 2006, 83-4)

Sin querer entrar en la descripción de aquellos mecanismos con los cuales un escritor bautiza a sus personajes, hay que ponderar la capacidad asociativa del chileno al vincular el nombre del personaje con el oso pardo (don Oso). Así de lúdicas son las estrategias antroponímicas del chileno que se evidencian en un mecanismo retórico de trasposición tan simple como trocar su apellido Bolaño por Belano o Monterroso por Montesol, o bautizar como Clara Cabeza a la ficticia secretaria de Octavio Paz.

La actitud tzántzica de reducir la cabeza de un "maestro" (palabra que aparece 78 veces) es notoria en el monumental libro de 622 páginas. Así son los poetas que abundan en Los detectives salvajes, mediocres a la sombra del boom, como dice Valencia, jóvenes que buscan subvertir el orden establecido y que ansían reducir la cabeza de los maestros reconocidos. El mismo Bolaño lo señala en el manifiesto infrarrealista, "Déjenlo todo nuevamente", que publicó en 1976:

Son tiempos duros para la poesía, dicen algunos, tomando té, escuchando música en sus departamentos, hablando (escuchando) a los viejos maestros. Son tiempos duros para el hombre, decimos nosotros, volviendo a las barricadas después de una jornada llena de mierda y gases lacrimógenos, descubriendo / creando música hasta en los departamentos, mirando largamente los cementerios-que-se-expanden, donde toman desesperadamente una taza de té o se emborrachan de pura rabia o inercia los viejos maestros. (Bolaño 2013, 55)

Más allá del aire revolucionario y rebelde, nótese en la cita la conciencia bolañesca de tener siempre en la mira de su rifle a "los viejos maestros" como él lo enfatiza. Actitud contestataria que luego se reflejará en la subversión como parte de la ética del realismo visceral conformado por poetas que roban libros, venden drogas para poder publicar una revista, andan con criminales y prostitutas. Como bien lo señala Juan Villoro: 
"Los infrarrealistas hasta la fecha fueron vistos como vagabundos delincuenciales" (2013).

Veamos ahora cómo Bolaño no solo que reduce la cabeza de Donoso Pareja, a la manera de los tzántzicos, sino que también usa la temible espada, al insertarlo como personaje en el episodio "Lisandro Morales, calle Comercio, enfrente del jardín Morelos, colonia Escandón, México DF, marzo de 1977". Morales es un exiliado ecuatoriano, director de una pequeña editorial y conoce a Belano a través de Vargas Pardo que está organizando una revista de literatura para promocionar a la editorial. El primer dardo es lanzado con agudeza hacia el amiguismo: "A mí me dieron el puesto de director honorario y Vargas Pardo y un par de sus amigotes se adjudicaron a dedo el consejo de redacción”. El segundo arpón va contra el contenido del primer número de la revista: "el resto de las colaboraciones eran de Vargas Pardo, un ensayo de un novelista exiliado en México amigo de Vargas Pardo, dos adelantos de sendas novelas que próximamente publicaríamos en la editorial, un cuento de un compatriota olvidado de Vargas Pardo, y poesía, demasiada poesía”. Sobre este género literario se lee lo siguiente en la nota preliminar ( $\sin$ firmar pero que sin dudas pertenece al editor) de la antología Muchachos desnudos bajo un arcoíris de fuego: "La poesía — tal vez la más alta expresión estética- es la cenicienta de la literatura. Y si es hecha por jóvenes todavía más. De ahí la necesidad de estimular su publicación". Es imposible no conectar esta cita con el interés del personaje ecuatoriano por la lírica: "A veces me preguntaba por qué al cabrón de Vargas Pardo le interesaba tanto la poesía. Él, me consta, no era poeta sino narrador. ¿De dónde, pues, le venía su interés por la lírica?”. Esta pregunta puede ser trastocada y lanzada al mismo Bolaño. Él, nos consta, no era narrador sino poeta. ¿¿De dónde, pues, le venía su interés por la narrativa? Habría entonces que ver su primera etapa poética como una suerte de experimentación para el relatista que se estaba gestando en él y que escribiría al final de 2666: “Toda la poesía, en cualquiera de sus múltiples disciplinas, estaba contenida, o podía estar contenida, en una novela".

El guayaquileño, en sus dos autobiografías, responde a las ficciones de Bolaño poniendo en evidencia la identidad de ese memorable Vargas Pardo. En A río revuelto: Memorias de un yo mentiroso, Donoso Pareja inventa un alter ego al que llama indistintamente El cadáver o El muerto. 
Evidentemente, Bolaño alude a la revista Cambio, y los amigotes de El muerto (Vargas Pardo) deben ser los integrantes de la dirección colectiva de esta: Cortázar, Pedro Orgambide, Revueltas, Rulfo y Eraclio Zepeda [...]

Este número de la revista apócrifa de Bolaño debe referirse a la cuarta entrega de Cambio, que apareció con un artículo central de Carlos Monsiváis "La dependencia y la cultura mexicana de los setentas". El escritor argentino exiliado al que alude debe ser Pedro Orgambide. Nada de él ni de El cadáver que hablaba aparece en este número, tampoco de ecuatoriano alguno, ni los anuncios de las novelas ni la demasiada poesía (solo se publican textos de dos poetas, el peruano Jorge Pimentel y el mexicano Alejandro Sandoval). (Donoso Pareja 2001, 302)

Se trata de una lectura chismográfica, como el mismo Donoso Pareja apunta al revelar, en las mismas memorias, que él inspiró el personaje de Silverio Lanza en El miedo a los animales del mexicano Enrique Serna. Lanza es un instructor de talleres literarios: "un escritor ecuatoriano que vivió aquí en los 70, con un sentido del humor formidable”, “Él nos enseñó el abecé de la literatura, desde donde poner los puntos y las comas hasta cómo escribir un monólogo interior". Como vemos en la anterior cita, se asume la postura del maestro, y al encaramarse en una cátedra se procede a la ostentación de un saber. Sin embargo, como el mismo Donoso Pareja lo señala en esas páginas, "todo esto es solo anécdota, lectura viciada, es decir, chismográfica".

En otro libro de memorias del escritor guayaquileño, La tercera es la vencida: Últimas palabras y el oscuro resplandor, hay todo un apartado dedicado a detectar supuestos errores gramaticales o sintácticos (pachotadas, bolañadas o belanadas, las llama el ecuatoriano) hallados en 2666, apartado que culmina con este apunte: “Observación del estribo: Melodrama barato para cerrar con broche de oro este museo del lugar común y del malagradecimiento más canalla" (Donoso Pareja 2011, 63).

Estamos ante un caso peculiar en el que el maestro es cuestionado en un texto de ficción y el mismo maestro procede a defenderse (o contraatacar) en un texto de no ficción. Todo se da a partir de ese sentirse aludido que Bolaño ya mencionó en su cuento "Una aventura literaria” y que forma parte de los hábitos de los creadores de ficciones: 
B escribe un libro en donde se burla, bajo máscaras diversas, de ciertos escritores, aunque más ajustado sería decir de ciertos arquetipos de escritores [...]

B, decíamos, escribe un libro y en uno de los capítulos se burla de A. La burla no es cruenta (sobre todo teniendo en cuenta que se trata solo de un capítulo de un libro más o menos extenso). (Bolaño 1997, 52)

Como vemos en esta cita, la burla es una actitud vital y artística esencial en Bolaño. Él no solo se mofa de otros escritores, ya sea en sus escritos o entrevistas para prensa y televisión, también lo hace con el género policial del cual toma prestados el tema de la búsqueda convirtiendo a Los detectives salvajes en una especie de contrapolicial donde ninguno de los enigmas planteados es resuelto. La ironía bolañesca (que es una actitud proveniente de las vanguardias) también apunta a valores sagrados de la literatura y el arte. De hecho, el nombre de real visceralistas, según García Madero, "de alguna manera es una broma y de alguna manera es algo completamente en serio" (Bolaño 1998, 17).

Quien no tiene cómo ejercer el derecho a la defensa propia es Octavio Paz, el gran blanco de la burla y al mismo tiempo de la admiración de Bolaño. El nombre del premio Nobel está en el segundo lugar en la lista de lo que más se repite en la novela (97 veces) y nos remite simbólicamente a César Augusto, también conocido como Octavio, primer emperador romano; y el de Cesárea (que se repite 68 veces) se puede ver como un guiño al mismo César mexicano, o sea, su contraparte femenina.

Los grandes opositores del emperador eran los real visceralistas, como bien se lo explica en "Luis Sebastián Rosado, cafetería La Rama Dorada, colonia Coyoacán, México DF, abril de 1976": "Por supuesto, en el panorama literario yo defendí en todo momento lo que hacía Octavio Paz. Por supuesto, a ellos solo parecía gustarles lo que hacían ellos mismos" (Bolaño 1998, 153). Paz era el blanco de los poetas no oficiales del México de los setenta:

En 1976 -luego de la constitución oficial del grupo poético- Roberto Bolaño invita a Sergio Loya a unirse al infrarrealismo. Interrogado por el poeta sobre el objetivo del movimiento, Bolaño responde: "Partirle su madre a Octavio Paz", frase que se ha convertido en un símbolo de la actitud de los infras para con la cultura oficial. (Cobas Carral 2006, 15) 
El poema "Horda", incluido en La universidad desconocida, es el que mejor "le parte la madre" a la poesía latinoamericana institucionalizada al criticar las prácticas de poder: "En el duro arte de sobrevivir a cambio de excrementos,/ De ejercicios públicos de terror, los Neruda/ Y los Octavio Paz del bolsillo/ los cerdos fríos, ábside/ O rasguño en el Gran Edificio del Poder" (Bolaño 2007, 292).

El maestro Paz es paradigma del intelectual omnisciente como lo vemos en la siguiente cita, a propósito de una mención a cuestiones de métrica española y retórica clásica, mencionadas por García Madero, como la perífrasis, la pentapodia, el nicárqueo y el tetrástico:

El único poeta mexicano que sabe de memoria estas cosas es Octavio Paz (nuestro gran enemigo), el resto no tiene ni idea, al menos eso fue lo que me dijo Ulises Lima minutos después de que yo me sumara y fuera amistosamente aceptado en las filas del realismo visceral. Hacerle estas preguntas a Álamo fue, como no tardé en comprobarlo, una prueba de mi falta de tacto. Al principio pensé que la sonrisa que me dedicó era de admiración. Luego me di cuenta que también era de desprecio. Los poetas mexicanos (supongo que los poetas en general) detestan que se les recuerde su ignorancia. Pero yo no me arredré y después de que me destrozara un par de poemas en la segunda sesión a la que asistía, le pregunté si sabía qué era un rispetto. Álamo pensó que yo le exigía respeto para mis poesías y se largó a hablar de la crítica objetiva (para variar), que es un campo de minas por donde debe transitar todo joven poeta, etcétera, pero no lo dejé proseguir y tras aclararle que nunca en mi corta vida había solicitado respeto para mis pobres creaciones volví a formularle la pregunta, esta vez intentando vocalizar con la mayor claridad posible. (Bolaño 1998, 14)

En este extenso testimonio de García Madero está el quid de la discusión sobre los maestros, ya que por un lado se ensalza al autor de Piedra de sol y por otro se pone en tela de juicio los conocimientos del instructor del taller. En una entrevista que le hace la televisión chilena en 1999, Bolaño revela mientras fuma incesantemente: "Detestábamos a Octavio Paz, pero es un gran poeta y uno de los ensayistas más lúcidos”. La larga cita de Los detectives salvajes da cuenta de la importancia del aprendizaje del poeta que debe sumergirse en la preceptiva literaria para no caer en esa ignorancia de la que habla García Madero. La respuesta de Julio César Álamo es la de despreciar al alumno que desea saber más del oficio. Sin embargo, García Madero valientemente enfrenta al instructor del taller literario: "Un 
rispetto, querido maestro, es un tipo de poesía lírica, amorosa para ser más exactos, semejante al strambotto, que tiene seis u ocho endecasílabos, los cuatro primeros con forma de serventesio y los siguientes construidos en pareados" (Bolaño 1998, 14).

En esta vuelta de revés constatamos cómo el alumno se convierte en el maestro. El novicio tallerista es el que da cátedra sobre retórica clásica. Su actitud es la de cuestionar al profesor hasta el punto de arrinconarlo. A este no le queda más que abandonar la conversación demostrando aquello de que "a los poetas les molesta que se les recuerde su propia ignorancia". Esta postura contestataria hacia la figura del maestro está vigente en toda la novela, sobre todo cuando Paz es puesto en la mira de un secuestro. Ulises Lima urde un plan que nunca logra concretarse pero que aparece como posibilidad en algunos episodios. Esta relación de Paz con sus detractores tiene su clímax en "Clara Cabeza, Parque Hundido, México DF, octubre de 1995". La voz pertenece a la secretaria del Premio Nobel 1990 que en clave paródica (solo hay que ver el nombre y el apellido de la mujer) ofrece su testimonio sobre lo que fue trabajar para Paz. En un momento este le confiesa a su asistente: "hace muchos años, Clarita, un grupo de energúmenos de la extrema izquierda planearon secuestrarme" (Bolaño 1998, 507). El resto del episodio se encarga de recrear el encuentro en el parque entre el premio Nobel y el cabecilla del grupo de energúmenos que lo cuestionaba:

Y entonces don Octavio, al tiempo que invitaba al tal Lima a tomar asiento, dijo: real visceralista, real visceralista (como si el nombre le sonara de algo), ¿no fue ese el grupo poético de Césarea Tinajero? Y el tal Lima se sentó junto a don Octavio y suspiró o hizo un ruido raro con los pulmones y dijo sí, así se llamaba el grupo de Cesárea Tinajero. (Bolaño 1998, 509)

El contenido de la conversación jamás se revela, pues Clara Cabeza toma su distancia. Al final acota que fue "una conversación serena, distendida y tolerante". Se trata de una simbólica firma de paz entre el maestro y el alumno.

Paz y Tinajero parecen ser anverso y reverso de una misma moneda. Ambos polos representan a la poesía latinoamericana en su dimensión tanto masculina como femenina. Esta última ha sido históricamente soslayada por el canon convirtiendo la búsqueda de Cesárea en un intento 
de inclusión de la mujer en un proyecto de escritura, labor que Bolaño luego continuará en Amuleto (1999) al representar en la figura de Auxilio Lacouture a la autoproclamada madre de la poesía mexicana.

Los detectives, Ulises Lima y Arturo Belano, buscan a la poeta cuyo apellido se remite a la tinaja, una enorme vasija cuya forma recuerda a la de un útero. De hecho, en las primeras páginas del diario de Juan García Madero se lee la primera mención al personaje:

Según Arturo Belano, los real visceralistas se perdieron en el desierto de Sonora. Después mencionaron a una tal Cesárea Tinajero o Tinaja, no recuerdo, creo que por entonces yo discutía con un mesero por unas botellas de cerveza, y hablaron de las Poesías del Conde de Lautréamont... (Bolaño 1998, 17)

El hálito de leyenda es tan poderoso en Tinajero que esta es nombrada por Octavio Paz cuando se encuentra con Ulises Lima en el Parque Hundido. El premio Nobel reconoce al joven poeta como parte del grupo de Tinajero. Ella es una mujer agraciada físicamente, según el testimonio de Salvatierra, pero "parecía una roca o un elefante", "una mole que apenas podía correr”, según García Madero, o simplemente “es el horror”, según otro personaje llamado Ernesto San Epifanio. Esta indefinición física en la descripción coincide con la ausencia de poemas escritos por ella cual si fuera un fantasma. Hay una pesquisa de Lima y Belano para conseguir textos de Tinajero para publicarlos en una revista, pero a duras penas logran encontrar un poema visual (a la manera futurista) titulado "Sión”.

En la búsqueda de la poeta hay un personaje clave, el de la colega de Tinajero (profesora en la misma escuela en la que ejercía de docente la veinteañera Cesárea en 1938). Ella les proporciona a Ulises y Arturo una clave fundamental:

Pero Cesárea habló de los tiempos que iban a venir y la maestra, por cambiar de tema, le preguntó qué tiempos eran aquéllos y cuándo. Y Cesárea apuntó una fecha: allá por el año 2600. Dos mil seiscientos y pico. (Bolaño 1998, 596)

Es importante el rol que Bolaño le ha asignado al personaje femenino: es una maestra escolar (de hecho, pertenece al magisterio gremial de Sonora) en contraposición con Octavio Paz que sería, según la categoría 
de Steiner, un maestro de lectura. La ciudad en la que es encontrada Cesárea resulta ser Santa Teresa, lugar que será el escenario de los homicidios de 2666 , cifra que es revelada como "dos mil seiscientos y pico" por Tinajero, según el testimonio de la colega.

Los dos "detectives" se convierten involuntariamente en asesinos apenas encuentran a la poeta: al llegar donde ella se evidencia su escondite y se da el tiroteo en el que ella muere accidentalmente. Tanto Lima como Belano se han convertido en salvajes cómplices del borroso homicidio de la escritora. Han llevado a la muerte a la madre del real visceralismo. Es el comienzo de la orfandad. La novela entra en sus últimas páginas en una simbólica cesárea que alumbra uno de los próximos escenarios novelescos de Bolaño, Santa Teresa, que en La parte de los crímenes albergará un sinfín de cadáveres femeninos. Hay que ver el asesinato de la poeta como el comienzo de la cadena de homicidios que tendrán lugar en La parte de los crimenes. Los detectives salvajes es nada más que el río narrativo que busca lugar en la matriz de Tinajero. En 2666 ese río se desbordará. Ella ocupa el lugar de lo legendario y lo invisible, en contraposición con la omnipresencia de Paz en ese mapa de la poesía latinoamericana que constituye esta novela salvaje.

En 2666, Bolaño dejará de lado las historias de poetas y de poesía y se dedicará a explorar las tradiciones literarias del siglo XX. El discípulo se ha convertido ya en un maestro. Los talleres literarios como espacio de ficción se han agotado. Ya no hay que buscar a Octavio Paz o a Cesárea Tinajero. Otros son los personajes que forman parte de la gran búsqueda.

\section{Lista de referencias}

Bolaño, Roberto. 1976. Pájaro de calor. Ciudad de México: Ediciones Asunción Sanchís.

—. 1997. "Una aventura literaria". En Llamadas telefónicas. Barcelona: Anagrama.

—. 1998. Los detectives salvajes. Barcelona: Anagrama.

—. 2001. "Gómez Palacio". En Putas asesinas. Barcelona: Anagrama.

- 2007. La universidad desconocida. Barcelona: Anagrama.

—. 2013. "Déjenlo todo nuevamente". En Nada utópico nos es ajeno. León, Guanajuato: Tsunun.

Campos, Javier. 2011. "El Primer Manifiesto de los Infrarrealistas" de 1976: su contexto y su poética en Los detectives salvajes". En Fernando Moreno, Roberto Bolaño: La experiencia del abismo. Santiago: Lastarria. 
KİPUS 49, enero-junio 2021

Cobas Carral, Andrea. 2006. "'La estupidez no es nuestro fuerte'. Tres manifiestos del infrarrealismo mexicano”. 2 Osa Mayor. Graduate Student Review (University of Pittsburgh): 11-29.

Donoso Pareja, Miguel. 1979. “Once poetas, seis países: ¿Poesía concreta o poesía en proceso?". En Roberto Bolaño, Muchachos desnudos bajo el arcoiris de fuego: once jóvenes poetas latinoamericanos. Ciudad de México: Extemporáneos.

- 2001. A río revuelto (memorias de un Yo mentiroso). Quito: Planeta.

- 2011. La tercera es la vencida. Últimas palabras y el oscuro resplandor. Quito: Ministerio Coordinador de Patrimonio.

Guzmán, Ivonne. 2014. "Miguel Donoso ha sido mi maestro y modelo de vida". El Comercio. 24 de noviembre.

Jahanbegloo, Ramin. 1994. George Steiner en diálogo con Ramin Jahanbegloo. Madrid: Anaya \& Mario Muchnik.

Steiner, George. 2011. La lecciones de los maestros. Madrid: Siruela.

Valencia, Leonardo. 2006. "Writing from Neverland”. El Búho (15): 83-4.

Villoro, Juan. 2013. "Pasado y futuro del Infrarrealismo”. En Nada utópico nos es ajeno (Manifiestos Infrarrealistas). León, Guanajuato: Tsunun.

Zambra, Alejandro. 2010. No leer. Crónicas. Ensayos sobre literatura. Santiago: Universidad Diego Portales. 